\title{
Altered resting-state functional connectivity in emotion-processing brain regions in adults who were born very preterm
}

\author{
C. Papini ${ }^{1{ }^{2 *}}$, T. P. White ${ }^{1,3}$, A. Montagna ${ }^{4}$, P. J. Brittain ${ }^{1}$, S. Froudist-Walsh ${ }^{1}$, J. Kroll ${ }^{1}$, V. Karolis ${ }^{1}$, \\ A. Simonelli ${ }^{2}$, S. C. Williams ${ }^{5}$, R. M. Murray ${ }^{1}$ and C. Nosarti ${ }^{1,2}$ \\ ${ }^{1}$ Department of Psychosis Studies, Institute of Psychiatry, Psychology and Neuroscience, King's College London, De Crespigny Park, London, UK \\ ${ }^{2}$ Department of Developmental Psychology and Socialisation, University of Padua, Padua, Italy \\ ${ }^{3}$ School of Psychology, University of Birmingham, Edgbaston, Birmingham, UK \\ ${ }^{4}$ Division of Imaging Sciences and Biomedical Engineering, Centre for the Developing Brain, King's College London, St. Thomas' Hospital, London, \\ UK \\ ${ }^{5}$ Department of Neuroimaging, Centre for Neuroimaging Sciences, Institute of Psychiatry, Psychology and Neuroscience, King's College London, \\ De Crespigny Park, London, UK
}

Background. Very preterm birth (VPT; $<32$ weeks of gestation) has been associated with impairments in emotion regulation, social competence and communicative skills. However, the neuroanatomical mechanisms underlying such impairments have not been systematically studied. Here we investigated the functional integrity of the amygdala connectivity network in relation to the ability to recognize emotions from facial expressions in VPT adults.

\begin{abstract}
Method. Thirty-six VPT-born adults and 38 age-matched controls were scanned at rest in a 3-T MRI scanner. Restingstate functional connectivity ( $\mathrm{rs}-\mathrm{fc}$ ) was assessed with SPM8. A seed-based analysis focusing on three amygdalar subregions (centro-medial/latero-basal/superficial) was performed. Participants' ability to recognize emotions was assessed using dynamic stimuli of human faces expressing six emotions at different intensities with the Emotion Recognition Task (ERT).

Results. VPT individuals compared to controls showed reduced rs-fc between the superficial subregion of the left amygdala, and the right posterior cingulate cortex $(p=0.017)$ and the left precuneus $(p=0.002)$. The VPT group further showed elevated rs-fc between the left superficial amygdala and the superior temporal sulcus $(p=0.008)$. Performance on the ERT showed that the VPT group was less able than controls to recognize anger at low levels of intensity. Anger scores were significantly associated with rs-fc between the superficial amygdala and the posterior cingulate cortex in controls but not in VPT individuals.
\end{abstract}

Conclusions. These findings suggest that alterations in rs-fc between the amygdala, parietal and temporal cortices could represent the mechanism linking VPT birth and deficits in emotion processing.

Received 16 November 2015; Revised 13 June 2016; Accepted 16 June 2016; First published online 15 August 2016

Key words: Emotion recognition, resting-state fMRI, very preterm birth.

\section{Introduction}

Very preterm birth (VPT, <32 weeks' gestation) has been associated with a higher risk of neurological and cognitive deficits (Bos \& Roze, 2011; Burnett et al. 2013), behavioural problems and learning difficulties (Johnson \& Marlow, 2011; Harmon et al. 2015). Individuals who were born VPT are vulnerable to socio-emotional impairments, including social

* Address for correspondence: C. Papini, Department of Psychosis Studies, Institute of Psychiatry, Psychology and Neuroscience, King's College London, De Crespigny Park, London, SE5 8AF, UK.

(Email: chiara.papini@kcl.ac.uk) isolation, peer rejection, poor social competence and shyness (Rickards et al. 2001; Dahl et al. 2006; Schmidt et al. 2008; Healy et al. 2013; Williamson \& Jakobson, 2014), as well as impairments in the ability to recognize facial emotions (Potharst et al. 2013; Witt et al. 2014). Social deficits have been described in the first 2 years of life in VPT samples (Spittle et al. 2009; Boyd et al. 2013); and furthermore, VPT children and adolescents have been found to have a higher risk of anxiety and depression (Burnett et al. 2011), attention deficit hyperactivity disorder (ADHD; Lindström et al. 2011) and autism (Limperopoulos et al. 2008; Pinto-Martin et al. 2011) compared to controls. Individuals born VPT continue to be at an increased risk for psychiatric disorders in adult life, with mood

This is an Open Access article, distributed under the terms of the Creative Commons Attribution licence (http://creativecommons.org/licenses/by/4.0/), which permits unrestricted re-use, distribution, and reproduction in any medium, provided the original work is properly cited. 
and anxiety disorders being the most prevalent (Walshe et al. 2008; Nosarti et al. 2012; D'Onofrio et al. 2013). Their typical personality profile, characterized by low risk-taking, neuroticism and introversion, might also predispose them to social vulnerability and difficulties in social interactions (Allin et al. 2006; Saigal, 2014; Eryigit-Madzwamuse et al. 2015).

As VPT birth is associated with early brain injury and aberrant trajectories of cerebral development (Ball et al. 2012), specific structural and functional brain alterations might underlie socio-emotional impairments. Volumetric alterations have been shown in VPT samples in brain regions thought to subserve emotion processing, such as the amygdala (Peterson et al. 2000), orbitofrontal cortex (Giménez et al. 2006), fusiform gyrus (Nosarti et al. 2008; Gousias et al. 2012), hippocampus (Rogers et al. 2012; Omizzolo et al. 2013; Aanes et al. 2015) and insula (Nosarti et al. 2014). Moreover, both structural magnetic resonance imaging (MRI) and diffusion MRI studies, have found significant associations between brain alterations in regions typically implicated in socioemotion processing and specific social and emotional outcomes in VPT samples (Rogers et al. 2012, 2014; Healy et al. 2013; Fischi-Gómez et al. 2015). However, to our knowledge, no neuroimaging study to date has investigated resting-state functional connectivity (rs-fc) in emotion-processing networks and performance on emotional processing tasks in individuals born VPT.

In this study, we probed the integrity of functional networks that are fundamental to emotional information processing and are anchored in the amygdala (Leppänen \& Nelson, 2009; Bickart et al. 2014). Functional connectivity between three amygdalar subregions (centro-medial/latero-basal/superficial) and all other brain areas was investigated using rs-fc MRI. In addition, we conducted an exploratory analysis to investigate participants' ability to recognize six basic emotions assessed with the Emotion Recognition Task (ERT; Montagne et al. 2007), a computer-based test that uses morphed images of human faces at different degrees of emotional intensity. In view of previous observations that amygdalar connectivity is reduced in individuals with mood disorders, and that this dysconnectivity relates to clinical symptoms and emotionprocessing performance (e.g. Peng et al. 2014), we hypothesized that VPT individuals would exhibit: (1) reduced rs-fc between the amygdala and key nodes of an emotion-processing network (Leppänen \& Nelson, 2009); (2) lower accuracy and longer reaction times than controls at recognizing emotions at lower intensity levels; and (3) functional integrity of the amygdala connectivity network would be related to performance on the ERT. Post-hoc exploratory analyses investigating associations between rs-fc, emotion recognition, full-scale IQ and perinatal variables were additionally conducted.

\section{Method \\ Participants}

We studied 36 participants recruited from a cohort of 218 individuals who were born at $<33$ weeks of gestation at University College London Hospital between 1979 and 1984 and who were enrolled into a follow-up study (Nosarti et al. 2008, 2014). Exclusion criteria were any history of neurological conditions including meningitis, head injury and cerebral infections.

Thirty-eight age-matched controls were recruited from advertisements in the local press and universities. Inclusion criteria were full-term birth (38-42 weeks of gestation) and birth weight $>2500 \mathrm{~g}$. Exclusion criteria were any history of birth complications (e.g. endotracheal mechanical ventilation), neurological conditions including meningitis, head injury and cerebral infections.

All participants gave informed written consent, were reimbursed for travel expenses and received a nominal remuneration for participation in the study. The study was given ethical approval by the Psychiatry, Nursing and Midwifery Research Ethics Subcommittee, King's College London.

\section{Materials}

IQ was assessed by the Wechsler Abbreviated Scale of Intelligence (WASI; Wechsler, 1999), which contains four subtests (Vocabulary, Similarities, Block Design and Matrix Reasoning) and provides estimates of verbal, performance and full-scale IQ. Processing speed and sustained attention were assessed using respectively correct response reaction times and omission errors from the Conner's Continuous Performance Test II (CCPT-II; Conners, 2000). Mental health at testing was evaluated with the General Health Questionnaire (GHQ-12; Goldberg \& Williams, 1988) and Peters' Delusional Inventory (PDI-21; Peters et al. 1999), that assess respectively anxiety/depression symptoms and psychosis proneness.

The ERT was used to evaluate the ability to identify six universal emotions (anger, disgust, fear, happiness, sadness, surprise) by using dynamic stimuli of human faces at different intensities. The stimuli set was developed from colour pictures of four Caucasian actors (two males and two females) in frontal view, who were asked to look neutral and to show a full-blown emotional expression. For each identity, a computer program created intermediate morphed images starting 
with an inexpressive frame and ending with an emotional expression of different intensities, ranging from $20 \%$ to $100 \%$ (Montagne et al. 2007). The ERT version used in this study included only four levels of intensity: $0-40 \%, 0-60 \%, 0-80 \%$ and $0-100 \%$.

The presentation procedure started with an instruction screen and a short practice trial with stimuli at 0-100\% intensity. The experimental task consisted of a total of 96 stimuli divided into four continuous blocks of increasing intensity. In each trial, one videoclip of a facial expression was played on the screen, the last frame of which represented a static image at the final emotional intensity. Then six labels, describing the six emotions, appeared on the screen and participants were requested to choose the one which was deemed to correspond to the preceding facial expression. No time restriction was imposed, but reaction times were recorded. Overall ERT administration duration was approximately $10 \mathrm{~min}$.

\section{Socio-demographic, perinatal, neuropsychological and ERT data analysis}

Statistical analyses were performed using SPSS v. 22.0 (IBM SPSS Statistics, USA). Group comparisons in terms of age at assessment and neuropsychological test scores were performed using independent-sample $t$ tests or their non-parametric equivalent. Sex distribution was tested with Pearson's $\chi^{2}$, whereas differences in socioeconomic status (SES) and ethnicity were explored with Fisher's exact test. Differences in neonatal characteristics and full-scale IQ between the VPT group and the larger sample of VPT participants studied at 19-20 years (Nosarti et al. 2014) were analysed with univariate analysis of variance (ANOVA).

ERT performance was analysed in terms of both accuracy, as the number of correctly labelled expressions per emotion per intensity (maximum $=4$ ), and mean reaction time for each emotion-intensity level. Both measures were analysed using univariate analysis of covariance (ANCOVA) adjusting for processing speed as defined earlier (CCPT-II correct-response reaction times). First, modulation of accuracy and reaction times were investigated in separate three-way mixed ANCOVAs with emotion type (six levels: anger, disgust, fear, happiness, sadness, surprise) and emotion intensity (four levels: very low $0-40 \%$, low $0-60 \%$, high $0-80 \%$, very high $0-100 \%$ ) as within-subjects factors and group (two levels: preterm $v$. control) as between-subject factor. Subsequently, a two-way mixed ANCOVA was performed for each emotion separately, with emotion intensity as within-subject factor and group as between-subject factor. GreenhouseGeisser correction was used for violations of sphericity. False discovery rate (FDR) correction was applied throughout the analyses to account for multiple comparisons.

\section{MRI data acquisition}

Neuroimaging data were acquired at the Maudsley Hospital (London) using a General Electric Signa HDx 3.0 T MR scanner (GE Healthcare, USA). Resting-state images were collected from a gradient-echo echo-planar sequence (TR/TE: $2000 / 30 \mathrm{~ms}$, flip angle: $75^{\circ}$, matrix $64 \times 64, \quad F o V=218 \mathrm{~cm}$ ) resulting in 256 whole-brain volumes contained 37 non-contiguous slices with 2.4-mm thickness, 1-mm interslice gap and 3.4-mm voxel resolution. Before the resting-state session, participants were instructed to remain still with gaze fixed on a central cross.

For spatial normalization and localization, highresolution T1-weighted anatomical images were also acquired using a SPGR pulse sequence with the following parameters: $\mathrm{TR}=7.1 \mathrm{~ms}, \mathrm{TE}=2.8 \mathrm{~ms}, \mathrm{TI}=450$, FOV $=280 \mathrm{~cm}$, flip angle $=20^{\circ}$, matrix $=256 \times 256,196$ slices, no interslice gap, slice thickness $=1.1 \mathrm{~mm}$, isotropic resolution $=1.1 \times 1.1 \times 1.1 \mathrm{~mm}^{3}$.

\section{MRI data pre-processing}

Images were processed and analysed in SPM8 (http:// www.fil.ion.ucl.ac.uk/spm/software/spm8/) running on Matlab 7.12 (MathWorks, USA). Data were slicetime corrected, spatially realigned, normalized to a sample-specific DARTEL template created on the basis of unified segmentation of individual anatomy (Ashburner, 2007), and smoothed with a $6 \mathrm{~mm}$ fullwidth at half-maximum (FWHM) isotropic Gaussian kernel.

\section{Head motion and artefact detection}

As recent studies have demonstrated resting-state fMRI metrics to be particularly sensitive to confounding effects of head motion (Power et al. 2012; Van Dijk et al. 2012), the Artifact Detection Tools (ART, www.nitrc.org/projects/artifact_detect/) were used to identify problematic time points. In particular, an image was defined as an outlier (artefact) if a participant's head movement differed by in excess of 0.5 $\mathrm{mm}$ (translation) or $0.02 \mathrm{rad}$ (rotation) from the previous frame, or if the global mean intensity in the image was $>3$ S.D. from the mean image intensity for the entire scan.

To preserve the temporal structure of the data, outlier volumes were not corrected or deleted from the time series, but rather modelled in the first level General Linear Model (GLM). A Mann-Whitney $U$ test revealed no significant difference between 
VPT-born $($ median $=2.50)$ and controls $($ median $=2.00)$ in the number of outlier volumes $(z=-0.607, p=0.544)$.

\section{Regions of interest (ROIs) definition}

Rs-fc MRI data were analysed using a seed-based approach and taking the amygdalar subcompartments (supported by convergent structural and functional observations; Bzdok et al. 2013) as ROIs. Three amygdalar seed regions were determined through stereotaxic probabilistic maps of cytoarchitectonic boundaries (Amunts et al. 2005), implemented in the SPM Anatomy toolbox (Eickhoff et al. 2005). The centromedial group included the central and medial nuclei; the laterobasal subregion consisted of the lateral, basolateral, basomedial, and paralaminar nuclei; the superficial group included the anterior amygdaloid area, the amygdalopyriform transition area, the amygdaloid-hippocampal area and the ventral and posterior cortical nuclei.

Only voxels with at least a $50 \%$ probability of belonging to one of these subregions were included, and those exceeding $50 \%$ probability for multiple subregions were assigned only to the region for which they had the highest probability of inclusion. Images of each subregion were created in the standard space (MNI) separately for left and right hemisphere to create a total of six ROIs.

\section{Rs-fc MRI seed-region analysis}

The Functional Connectivity toolbox (CONN v14.b) (Whitfield-Gabrieli \& Nieto-Castanon, 2012; http:// web.mit.edu/swg/software.htm) was used to perform all seed-based analyses. To remove physiological noise and movement confounds, the CONN toolbox uses the anatomical component correction (aCompCor) strategy (Behzadi et al. 2007) that increases the sensitivity and specificity of positive correlations and can detect non-artifactual anti-correlations. Global signal regression was excluded to avoid the introduction of artificial negative correlation (Murphy et al. 2009). Subjectspecific effects of motion (defined by six realignment parameters and their first-order temporal derivatives), outliers volumes (represented by a binary regressor), and white matter and CSF signals (characterized by the first five principal components of each) were removed from the functional data using linear regression and the resulting residual blood oxygen-level dependent (BOLD) time series were band-pass filtered between 0.009 and $0.08 \mathrm{~Hz}$.

In the first-level analyses, the average BOLD timecourse was extracted from each seed region separately and Pearson's correlation coefficients were computed between that time course and the time course of every other voxel in the brain. Seed-to-voxel connectivity maps were constructed for each subject. Correlation coefficients were then converted to normally distributed $z$ scores using the Fisher transformation to allow the second-level GLM analyses. Within-group statistical parametric maps (SPMs) and connectivity differences between groups were further explored and examined with independent-sample $t$ tests. Reported clusters survived a height threshold of uncorrected $p<$ 0.001 and an extent threshold of FDR-corrected $p<0.05$ at cluster level.

\section{Associations between rs- $f_{c}$ MRI and ERT, socio-demographic, neuropsychological and perinatal data}

To evaluate relationships between rs-fc MRI data and emotion-processing performance, post-hoc correlation analyses were conducted. In these analyses, correlations between connectivity of significant clusters obtained during second-level analyses and ERT emotion recognition accuracy were assessed with Spearman's rank test.

Multiple analyses of variance were used to test for the effects of sex and SES, as well as interactions with group, in terms of ERT metrics and rs-fc patterns found to be different between preterm and control participants.

Other associations between $\mathrm{rs}-\mathrm{fc}$, full-scale IQ and perinatal factors were assessed using Pearson's correlation coefficient for parametric continuous variables.

\section{Results}

\section{Sample characteristics}

Characteristics of study sample are reported in Table 1. Controls tended to belong to higher SES compared to VPT individuals and about one quarter (26\%) of controls was recruited from the university campus (three post-doctoral researchers, three research workers/technicians, four postgraduate students). In terms of neuropsychological and mental health outcomes, compared to controls, VPT participants had significantly lower verbal, performance and full-scale IQ, despite their values falling within the test norm. No statistically significant between group differences were found in processing speed, sustained attention, or current mental health (GHQ-12 and PDI-21).

In order to assess selection bias in the VPT sample, we compared demographic and perinatal characteristics between the current VPT sample and a sample of 68 individuals who were assessed at age 19-20 (Nosarti et al. 2014). There were no statistically significant differences between the two VPT cohorts in terms of gestational age $\left(F_{1,102}=0.24, p>0.05\right)$ and birth weight $\left(F_{1,102}=0.85, p>0.05\right)$, although the current cohort had higher full-scale IQ than the VPT cohort assessed at age 19-20 $\left(F_{1,102}=7.29, p<0.01\right)$. 
Table 1. Sample characteristics. Frequencies, percentages and mean values (standard deviations) are given, unless otherwise specified

\begin{tabular}{|c|c|c|c|}
\hline & $\operatorname{VPT}(N=36)$ & Controls $(N=38)$ & Statistics \\
\hline \multicolumn{4}{|c|}{ Demographic and neonatal characteristics } \\
\hline Sex (male/female) & $20 / 16$ & $17 / 21$ & $\chi_{1}^{2}=0.87, p=0.352$ \\
\hline Age at assessment (years) & $30.25(2.31)$ & $29.16(3.64)$ & $t_{72}=1.53, p=0.130$ \\
\hline Birth weight $(\mathrm{g})$ & $1295.44(358.93)$ & N.A. & N.A. \\
\hline Gestational age (weeks) & $29.08(2.34)$ & N.A. & N.A. \\
\hline \multicolumn{4}{|l|}{ Socioeconomic status ${ }^{\mathrm{a}}$} \\
\hline $\mathrm{I}-\mathrm{II}$ & $47.2 \%$ & $71.1 \%$ & Fisher's exact test $=10.47, p=0.020$ \\
\hline III & $25 \%$ & $15.8 \%$ & \\
\hline IV-V & $8.3 \%$ & $0 \%$ & \\
\hline Student & $2.8 \%$ & $10.5 \%$ & \\
\hline Unemployed/out of work & $16.7 \%$ & $2.6 \%$ & \\
\hline \multicolumn{4}{|l|}{ Ethnicity } \\
\hline Caucasian & $80.6 \%$ & $84.2 \%$ & Fisher's exact test $=2.89, p=0.647$ \\
\hline African & $0 \%$ & $2.6 \%$ & \\
\hline Afro-Caribbean & $0 \%$ & $2.6 \%$ & \\
\hline Indian subcontinent & $11.1 \%$ & $5.3 \%$ & \\
\hline Other & $8.3 \%$ & $5.3 \%$ & \\
\hline \multicolumn{4}{|l|}{ Neonatal US classification $^{\mathrm{b}}$} \\
\hline Normal & 17 & N.A. & N.A. \\
\hline Uncomplicated PVH & 9 & N.A. & N.A. \\
\hline $\mathrm{PVH}+\mathrm{DIL}$ & 10 & N.A. & N.A. \\
\hline \multicolumn{4}{|l|}{ Neuropsychological assessment } \\
\hline Full-scale IQ & $103.94(14.08)$ & $113.68(10.62)$ & $t_{72}=3.37, p=0.001$ \\
\hline Verbal IQ & $100.72(15.01)$ & $110.66(12.51)$ & $t_{72}=3.01, p=0.003$ \\
\hline Performance IQ & $106.33(14.17)$ & $114.00(9.34)$ & $t_{72}=2.76, p=0.008$ \\
\hline Processing speed & $421.67(58.53)$ & $415.26(57.82)$ & $t_{72}=0.47, p=0.637$ \\
\hline Sustained attention ${ }^{c}$ & $1.50(1.64-6.36)$ & $2.00(2.12-4.25)$ & $U=607.00, p=0.399$ \\
\hline \multicolumn{4}{|l|}{ Mental health assessment } \\
\hline GHQ-12 ${ }^{c}$ & $2.00(2.04-4.51)$ & $1.50(1.21-3.42)$ & $U=558.00, p=0.160$ \\
\hline PDI-21 ${ }^{\mathrm{c}}$ & $22.50(22.92-45.80)$ & $10.00(13.58-32.37)$ & $U=535.50, p=0.107$ \\
\hline
\end{tabular}

VPT, Very preterm birth.

${ }^{a}$ Socioeconomic status classified according to the Standard Occupational Classification 1980 (SOC1980). The following categories were used: $\mathrm{I}-\mathrm{II}=$ managerial and professional; $\mathrm{III}=$ intermediate (e.g. small employers and own account workers); $\mathrm{IV}-\mathrm{V}=$ working (e.g. lower supervisory and technical occupations, routine and semi-routine occupations).

${ }^{\mathrm{b}}$ Periventricular haemorrhage was classified as haemorrhage into the germinal layer or lateral ventricles and ventricular dilatation as clear dilatation of one or both lateral ventricles with cerebrospinal fluid, although not sufficient to meet the conditions for a diagnosis of hydrocephalus (Stewart et al. 1983).

${ }^{\mathrm{c}}$ Median and $95 \%$ confidence intervals.

\section{Emotion Recognition Task}

Preterm participants' and controls' performance on the ERT in terms of accuracy and reaction time are displayed in Fig. $1(a, b)$.

Regarding accuracy, a three-way mixed ANCOVA demonstrated a trend towards a significant main effect for group $\left(F_{1,71}=3.13, p=0.081\right)$, with controls tending to perform better than VPT adults. Interactions between group and emotion type $\left(F_{5,355}=1.11, p=0.352\right)$ and emotion intensity $\left(F_{3,213}=1.84, p=0.149\right)$ were not significant. When analysing each emotion separately, a significant main effect for group $\left(F_{1,71}=9.05, p=0.024\right)$ and the interaction between group and emotion intensity $\left(F_{3,213}=5.86, p=0.006\right)$ were found only for anger. Further ANCOVAs showed that VPT adults were less able than controls to recognize anger at the lowest level of intensity; i.e. the most difficult condition $\left(F_{1,71}=23.41, p<0.0001\right.$; Fig. $\left.1 c\right)$.

Considering reaction time, a three-way mixed ANCOVA demonstrated a significant main effect for group $\left(F_{1,71}=8.48, p=0.005\right)$, with controls being faster than VPT participants. There was also a significant interaction between group and emotion intensity $\left(F_{3,213}=7.01, p=0.005\right)$, showing that controls were 


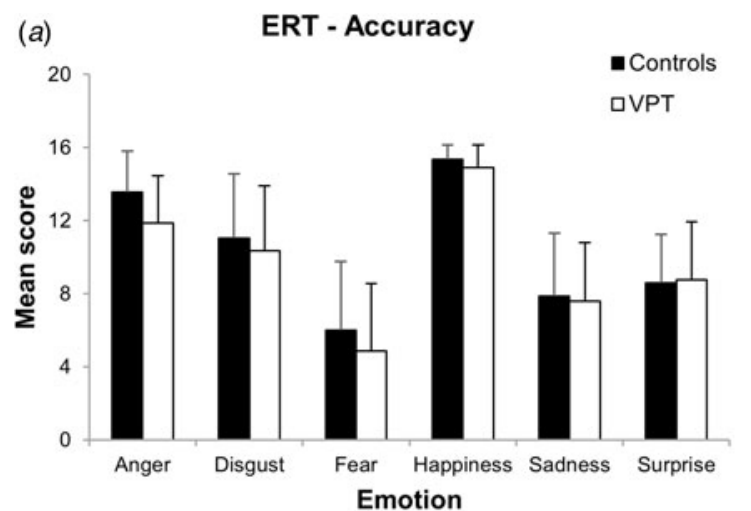

(c)

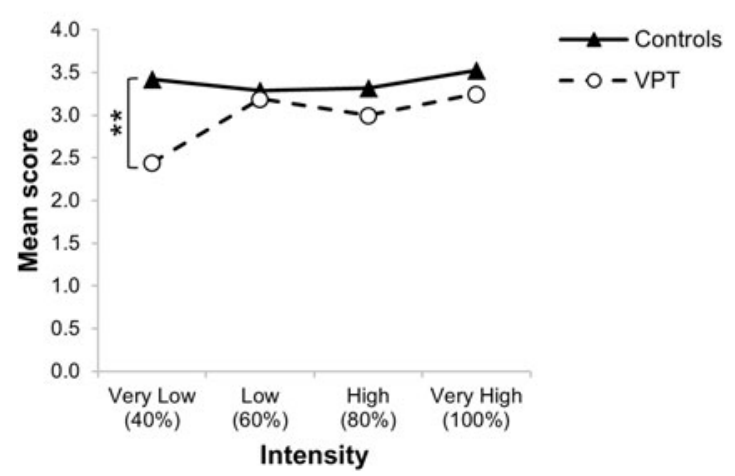

(b)

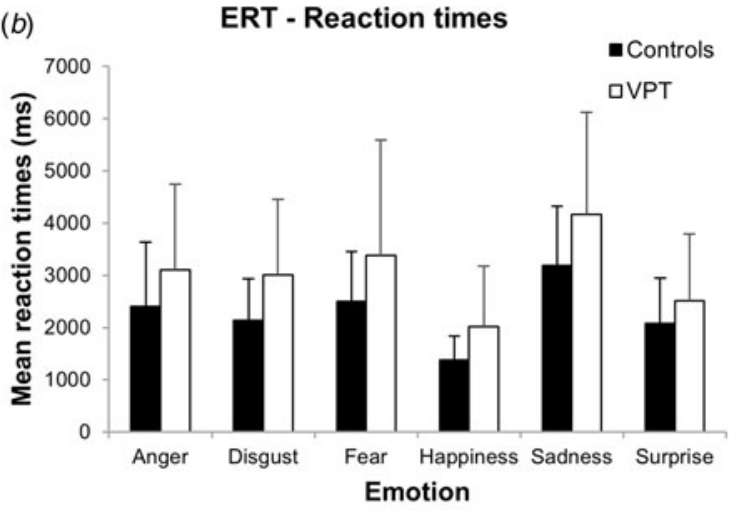

(d)

Anger - Reaction times

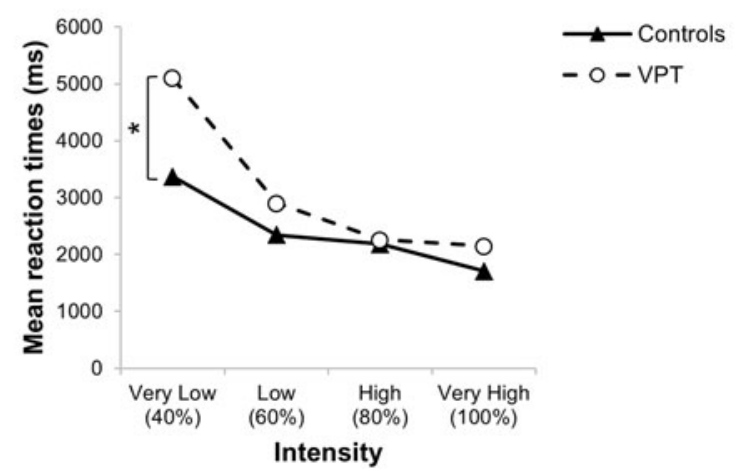

Fig. 1. Emotion Recognition Task (ERT) performance. (a) Mean scores and (b) mean reaction times of very preterm birth (VPT) participants and controls for the six ERT emotions. Error bars represent 1 standard deviation. $(c)$ Mean scores and $(d)$ mean reaction times of VPT participants (white dots) and controls (black triangles) at the four levels of intensity for anger. ${ }^{*} p<0.05,{ }^{* *} p<0.001$.

faster than VPT participants at each level of intensity, with reaction times progressively decreasing as the emotion became more obvious (e.g. at higher levels of intensity). When analysing each emotion separately, as it was done for accuracy, there was a significant interaction between emotion intensity and group only for anger, after FDR-correction $\left(F_{3,213}=5.55, p=0.042\right)$. Further ANCOVAs showed that VPT adults were slower than controls at recognizing anger at the lowest level of intensity $\left(F_{1,71}=7.15, p=0.036\right.$; Fig. $\left.1 d\right)$.

\section{Rs-fc MRI results}

Within group rs-fc MRI results

Within-group connectivity maps and significant areas of activation across the six amygdalar subregions (three in each hemisphere) are presented in Supplementary Fig. S1. In brief, spontaneous activity in the amygdala subregions was positively associated with neuronal activity in surrounding structures and the ventromedial prefrontal cortex, whereas it was negatively associated with neuronal activity in dorsal prefrontal cortex, parietal lobe and posterior brain regions, with strong inter-hemispheric similarities.

\section{Between-group rs-fc MRI results}

Significant between-group differences in patterns of rs-fc were found only for connectivity of the left superficial amygdalar subregion. This area showed hypoconnectivity with the right posterior cingulate cortex (PCC) and the left precuneus (pC) and hyperconnectivity with the superior temporal sulcus (STS) in VPT adults compared to controls (Table 2, Fig. 2).

\section{Investigating associations between $r s-f c$ MRI and facial emotion processing, sex, SES, IQ and perinatal risk factors}

In controls, anger scores were significantly associated with rs-fc between the left superficial amygdala and the PCC (Spearman's $\rho=0.426, p=0.008$ ), whereas in the VPT group this association was not significant (Spearman's $\rho=0.172, p=0.316$; Fig. 3). However, the correlation was not significantly different between the groups $(z=1.16, p=0.246)$.

Post-hoc analyses to assess the effect of sex and SES demonstrated no statistically significant differences between males and females, nor between SES categories on rs-fc patterns and ERT emotions where differences 
Table 2. Differences in functional connectivity of the left superficial amygdala between VPT individuals and controls

\begin{tabular}{|c|c|c|c|c|c|c|c|}
\hline \multirow[b]{2}{*}{ Contrast } & \multirow[b]{2}{*}{ Location (hemisphere) } & \multirow[b]{2}{*}{ Cluster size } & \multirow[b]{2}{*}{ Cluster $p$ value } & \multicolumn{3}{|c|}{ MNI coordinates } & \multirow{2}{*}{$\begin{array}{l}\text { Peak voxe } \\
t \text { statistic }\end{array}$} \\
\hline & & & & $\mathrm{x}$ & $\mathrm{y}$ & $\mathrm{z}$ & \\
\hline \multirow[t]{6}{*}{ VPT $<$ Controls } & Cingulate gyrus (R) & 148 & 0.017 & 20 & -26 & 44 & 5.13 \\
\hline & & & & 16 & -34 & 48 & 5.07 \\
\hline & & & & 22 & -16 & 44 & 3.83 \\
\hline & & & & 16 & -16 & 42 & 3.48 \\
\hline & Precuneus (L) & 238 & 0.002 & -10 & -70 & 60 & 4.29 \\
\hline & & & & -14 & -76 & 44 & 3.85 \\
\hline VPT $>$ Controls & Superior temporal gyrus (R) & 166 & 0.008 & 62 & -28 & 0 & 5.15 \\
\hline
\end{tabular}

VPT, Very preterm birth; R, right hemisphere; L, left hemisphere.

Reported clusters survived a height threshold of uncorrected $p<0.001$ and an extent threshold of FDR-corrected $p<0.05$ at the cluster level.

between preterm participants and controls were detected (all $p>0.05$ ).

Analysis of the association between rs-fc and full-scale IQ in VPT participants and controls did not show any statistically significant result (see Supplementary Table S1).

Within the VPT participants, perinatal risk factors (e.g. gestational age, birth weight and neonatal ultrasound classification) did not significantly correlate with either ERT performance or rs-fc patterns.

\section{Discussion}

Several investigations have suggested an association between atypical social development and VPT. This study provides two important contributions that help to elucidate the mechanisms underlying a possible link between the two. First, our results suggest that in adulthood VPT individuals display functional alterations in brain circuits fundamental to emotion processing; second, they demonstrate that VPT adults are worse than controls at recognizing subtle specific emotions from facial expressions.

Recognizing facial expressions denoting specific emotions is a crucial skill for successful interpersonal interactions and is compromised in many psychiatric disorders with onset in childhood/adolescence (Law Smith et al. 2010; Jarros et al. 2012; Collin et al. 2013) and adulthood (Scholten et al. 2005; Montagne et al. 2006, 2008; Poljac et al. 2011). In this study, findings from the overall ERT demonstrated that, compared to controls, VPT-born individuals had almost intact ability, but longer reaction times, at recognizing emotion expressions. This could be interpreted as a compensatory mechanism in VPT adults, who need more time to adequately process emotional stimuli. A more detailed analysis of emotion type found specific and subtle impairments in VPT adults in recognizing anger at very low intensity, with their performance being both slower and less accurate than controls. Importantly, in the current study these results are unlikely to depend on VPT participants' deficits in attention/processing speed or psychological distress, as their scores on such measures were comparable to controls'. These findings suggest that deficits in emotion recognition - previously reported generically at the age of $\leqslant 5$ years (Potharst et al. 2013; Witt et al. 2014) and specifically for anger and low-intensity stimuli at 8 years (Wocadlo \& Rieger, 2006) - persist into adulthood in VPT-born individuals. In the literature, a selective impairment in recognizing angry expressions has been associated with lower social competence in children across different ages (Maxim \& Nowicki, 2003). Diminished social competence could further result in social isolation and rejection by peers, as reported in VPT adolescent samples (Rickards et al. 2001; Dahl et al. 2006). Additionally, a reduced ability to recognize a potential threat conveyed by angry faces may make children more vulnerable to being bullied by peers (Woods et al. 2009), placing VPT samples at risk of experiencing bullying and related emotional problems (Wolke et al. 2015).

Even though these results suggest a selective difficulty for anger, the null findings in other emotions are likely to be due to a small sample size and the fact that the current VPT participants were cognitively unimpaired individuals (i.e. had IQ scores within the test norm). The possibility that VPT participants would also show subtle deficits for other emotions cannot be excluded by the current results and warrants testing in a larger sample with more variable psychosocial functioning. Moreover, a precise measure of participants' mood at testing would potentially mitigate potential bias effects on emotion processing. 

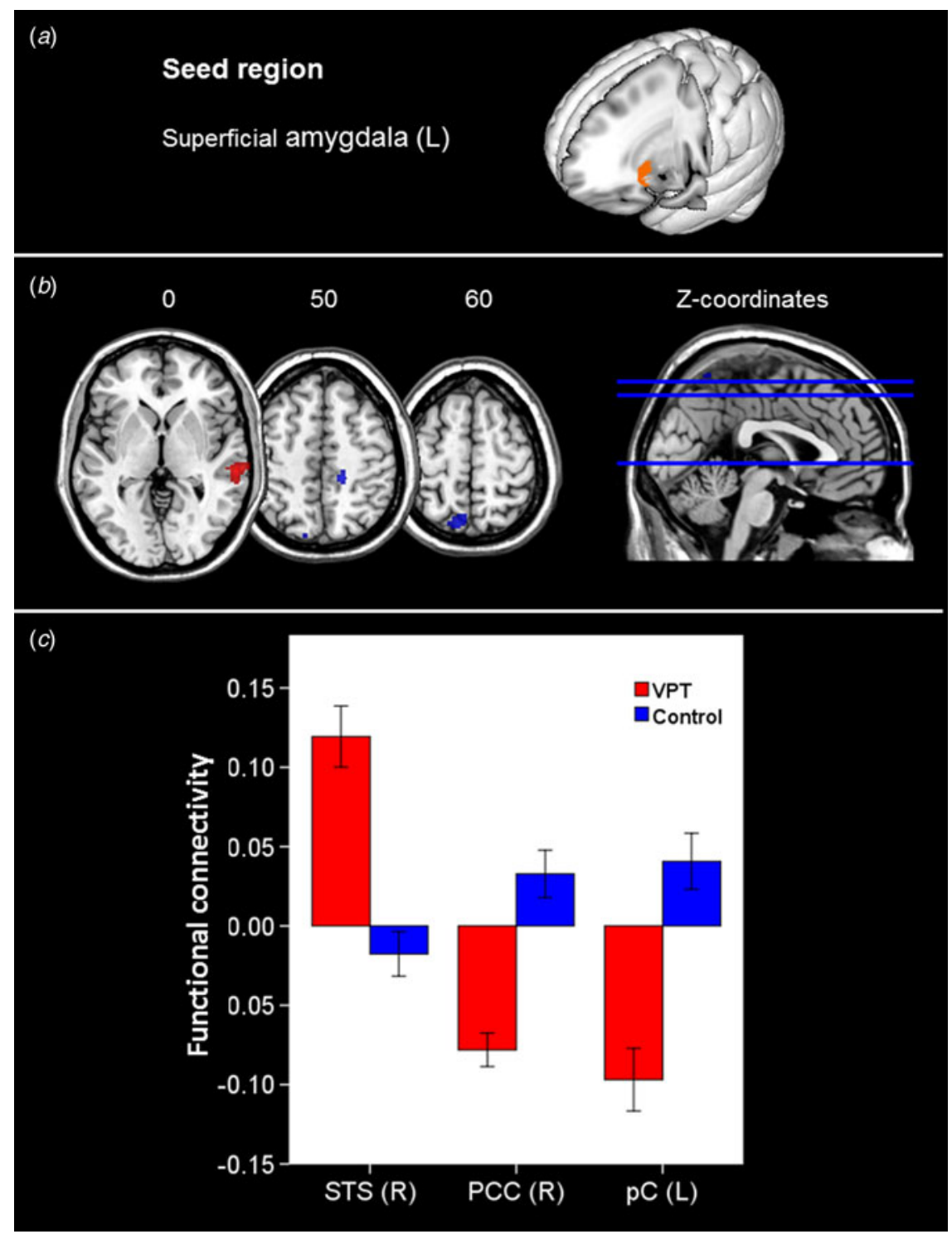

Fig. 2. Alterations in functional connectivity of the left superficial amygdala in very preterm birth (VPT) individuals compared to controls. (a) Location of $50 \%$ probabilistic masks of the superficial amygdala of the left hemisphere projected on the MNI template with neurological convention. (b) Brain areas that showed significantly greater functional connectivity of the left superficial amygdala in VPT individuals (hot colour scale) comprised the right superior temporal sulcus (STS); brain areas that showed significantly smaller functional connectivity of the left superficial amygdala in VPT individuals (cool colour scale) comprised the right posterior cingulate cortex (PCC) and the left precuneus (pC). Brain slices are displayed axially according to neurological convention, with $\mathrm{z}$ coordinates in MNI space above each slice. The figure on the right depicts these slices in blue on a midline, sagittal slice. Reported clusters survived a height threshold of uncorrected $p<0.001$ and an extent threshold of FDR-corrected $p<0.05$ at the cluster level. (c) Bar graph showing direct comparison of functional connectivity strength between the two groups. The y-axis indicates correlation coefficients between the time series of the seed region (superficial subregion of the left amygdala) and the time series extracted from the regions displaying significant between-group differences; the error bars represent 1 standard error.

To investigate the neural underpinnings of the observed behavioural deficits, whole-brain rs-fc analyses were conducted using seeds in three cytoarchitectonic subdivisions of the amygdala (and thus permitting dissociation of regionally specific connectivity patterns). Indeed, the superficial subregion of the left amygdala was unique in showing evidence of altered rs-fc in VPT participants compared to controls. While control subjects exhibited significant positive connectivity between this region and $\mathrm{pC}$ as well as PCC, VPT-born individuals displayed significant negative functional connectivity between the same regions. 


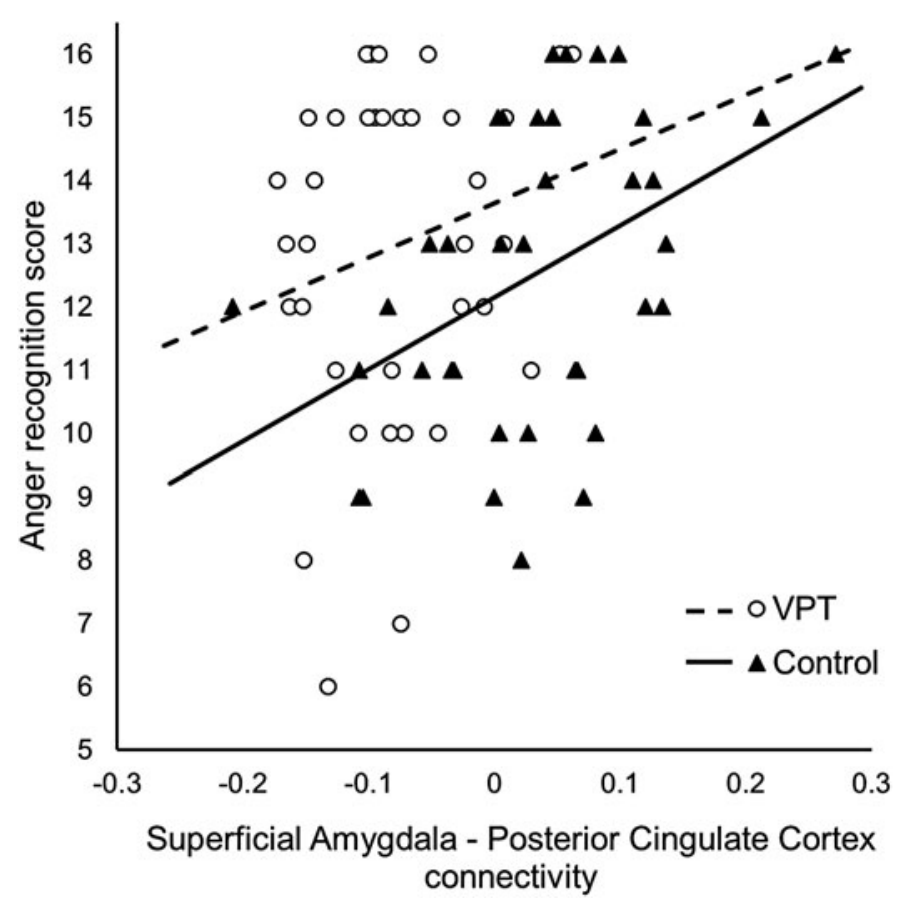

Fig. 3. Correlation between superficial amygdala-posterior cingulate connectivity and Emotion Recognition Task score for anger in very preterm birth (VPT) participants (white dots; Spearman's $\rho=0.172$ ) and controls (black triangles; Spearman's $\rho=0.426$ ). Least-squared lines are shown for illustrative purposes only and do not constitute a formal test.

VPT-born participants also showed increased connectivity between left superficial amygdala and the STS. Functional aberrations specific to this amygdalar compartment are not unexpected in light of recent meta-analytical findings (Bzdok et al. 2013) which reported that the superficial amygdala is highly tuned for processing both static and dynamic social stimuli in the form of emotional expression of human faces (Hurlemann et al. 2008; Goossens et al. 2009), and structural alterations of this subregion have been described in anxiety disorder (Qin et al. 2014).

Consistent with previous findings from healthy subjects (Roy et al. 2009), both groups in the current study displayed negative correlations between activity in amygdala and dorsolateral prefrontal and posterior parietal regions typically involved in cognitive control of emotions. However, VPT-born individuals displayed a wider suppression of posterior areas, which extended to a larger proportion of the PCC and the bilateral $\mathrm{pC}$. Aberrant amygdala-PCC/pC coupling has been previously reported in psychiatric samples with reduced connectivity associated with state anxiety scores (Hahn et al. 2011) and elevated connectivity found in individuals diagnosed with major depressive disorder (Cullen et al. 2014). The PCC and pC are involved in emotional evaluation (Wright et al. 2008) and modulation (Adolphs, 2003), and also constitute core regions of the 'default mode network' (DMN), a system that is more active at rest than during goal-oriented tasks (Raichle et al. 2001; Greicius et al. 2003). Increasing evidence demonstrates a substantial overlap between the DMN and the 'social brain' (Mars et al. 2012) and a relationship of reciprocal inhibition has been proposed between the cognitive and emotional systems (Drevets \& Raichle, 1998). We previously showed alterations in rs-fc between posterior DMN and salience network in VPT adults from the same cohort compared to controls (White et al. 2014). In this framework, hypoconnectivity between the amygdala and the PCC/pC in VPT-born individuals could hint at an altered coupling of these two regions. It is feasible that amygdalar activation in socioemotional relevant conditions might excessively suppress the activity of DMN brain regions responsible for cognitive evaluation of a given situation. This interpretation is in line with the study by Sreenivas et al. (2012), which reported a deactivation of DMN regions during the processing of emotional faces and, in particular, a greater deactivation for negative compared with positive emotions, as a demonstration of their higher evolutionary saliency. An increased negative coupling between the amygdala and the $\mathrm{PCC} / \mathrm{pC}$ could represent an overactive inhibitory connection that could become disruptive and maladaptive, not only in 'spectatorial' and experimental tasks, but also in emotionally-engaged and interactive settings in 
real life (Schilbach et al. 2013), as there exists a large topological overlap of brain regions involving such processes.

The current study suggests that the pathway between PCC and amygdala importantly contributes to emotion recognition. Connectivity between PCC and the left superficial amygdala was significantly associated with the ability to recognize angry faces in controls but not in VPT individuals, and suggests this as a potential substrate for selective ERT impairments in the latter. As the dorsal PCC plays a key modulatory role in the amygdala network for emotion processing (Pessoa et al. 2005; Stein et al. 2007), it can be reasonably hypothesized that the inability to recognize low intensity levels of anger may result from inadequate amygdalar modulation in VPT-born individuals. This has potential implications for social cognition, especially in situations where it is necessary to attribute mental states to others (Saxe \& Powell, 2006). The PCC is a highly connected structure (Hagmann et al. 2008) responsible for self-referential thought (Johnson et al. 2002; Mason et al. 2007; Buckner et al. 2008; Whitfield-Gabrieli et al. 2011), but is also involved in cognitive processes (Pearson et al. 2011). It acts as a connector hub in cortico-subcortical networks (Leech et al. 2012); and has been found to influence activity in distributed networks responsible for performing goal-directed actions, such as the dorsal attention network, fronto-parietal control network and salience network (Leech \& Sharp, 2014). In particular, the dorsal PCC is involved in allocating attentional focus and balancing between internally- and externally-oriented cognition (Leech et al. 2011, 2012). Thus, socio-emotional deficits in VPT-born individuals may result from difficulties in coordinating activity between systems responsible for processing emotion and those responsible for attention modulation. Impairments in executive function are widely recognized in VPT-born individuals across the life span (Aarnoudse-Moens et al. 2009; Burnett et al. 2013; Sølsnes et al. 2014) and these have been hypothesized as a potential mechanism to understand socio-emotional difficulties in VPT children (Hille et al. 2001). In other words, difficulties with adaptability, impulsivity, and attention could affect social interactions. Although our current analyses showed significant between group differences in ERT performance after accounting for sustained attention, it remains to be investigated whether impaired modulation of different aspects of attention (e.g. attentional control) which were not measured in the current study affect emotion recognition in VPT samples (Eack et al. 2016).

This study additionally presents evidence of connective pathways supporting emotional processing that are specific to individuals born VPT. Most notably, increased connectivity was found between the left superficial amygdala and the STS in this group but not in controls. Structural alterations in the STS have been previously reported in VPT samples (Nosarti et al. 2008; Rogers et al. 2014). This region - and in particular its posterior portion (Hein \& Knight, 2008)- is well known as a face-sensitive region specialized for dynamic feature recognition (Haxby et al. 2000; Andrews \& Ewbank, 2004; Engell \& Haxby, 2007), including eye and mouth movements (Puce et al. 1998; Hoffman \& Haxby, 2000) and emotional expressions (LaBar et al. 2003). Together with the amygdala and the orbitofrontal cortex, the STS has been proposed as a key region in social cognition (Brothers, 1990; Allison et al. 2000). Decreased connectivity between the amygdala and the STS has been hypothesized as the underlying mechanism of emotion and face processing disturbance in various psychiatric disorders, including autism spectrum disorder (Monk et al. 2010) and major depressive disorder (Ramasubbu et al. 2014). By contrast, the increased amygdala-STS connectivity found in our VPT-born sample could represent a compensatory strategy in a suboptimally efficient emotional network, facilitating emotion recognition by means of stronger integration between decoding of facial characteristics by the temporal areas and emotional salience by the amygdala. This interpretation could also explain the overall slower and less accurate performance of VPT adults on the ERT. Moreover, as the STS is crucial for theory of mind (Gallagher \& Frith, 2003; Vander Wyk et al. 2009), hyperconnectivity of this region with the amygdala could also support higher cognitive processing of emotional information.

\section{Strengths, limitations and future directions}

There are several limitations in this study. First, the amygdala, which was chosen as a seed region for rs-fc analyses, is susceptible to EPI image distortion and signal dropout, which may cause relevant problems of spatial localization (Merboldt et al. 2001). To deal with this potential bias, only the core of each amygdalar subregion was considered by using a probabilistic map at 50\%, as in Roy et al. 2009, but a stricter threshold could have been used (e.g. $90 \%$, as in Ball et al. 2007). Second, a score range between 0 and 4 at each ERT level of emotion did not allow us to explore subtler impairments in emotion recognition in relation to altered patterns of amygdalar connectivity. An increased number of trials or the use of more numerous levels of emotional intensity to further aggregate could have refined our analyses. Finally, the fact that controls tended to belong to higher SES bands compared to VPT individuals could have influenced our findings, although the current sample included high 
performing VPT adults (reflected by their higher IQ scores compared to a larger VPT sample assessed at age 18-19 years), who nevertheless had significantly lower IQ than controls. Replication of the study with a larger sample size might address these issues and provide a means of uncovering additional subtle features on account of increase statistical power.

Strengths of our study include: (1) a choice of amygdalar subdivisions used to define seed regions for rs-fc analysis, that permitted the investigation of betweengroup differences that could not have been detected considering the whole amygdala; (2) the use of DARTEL toolbox, that achieved a more accurate registration and normalization to account for structural differences expected between VPT-born individuals and born-at-term controls; and (3) the use of the ERT, which contains dynamic facial information, rather than fully blown and/or static information, which has proved advantageous in terms of identification of emotional expressions, evaluations of intensity and arousal, and discrimination of authenticity (Krumhuber et al. 2013), making it a useful tool to detect subtle and selective impairment that previous research failed to find (e.g. Ogai et al. 2003).

Future studies in VPT samples could investigate other critical skills that rely on emotion perception and contribute to the understanding of the complexity of the social world, such as attributing mental states, deciphering emotional meanings, using emotions in thought, and managing emotions (Mayer et al. 2001). These components could differentially contribute to behavioural and psychiatric problems and they are still unexplored in VPT populations. Potential interventions that aim at improving socio-emotional skills could then strengthen different components of emotional intelligence (e.g. Bölte et al. 2015).

\section{Conclusion}

VPT individuals continue to display subtle emotion recognition deficits in adulthood, which are associated with functional alterations in brain circuits fundamental to emotion processing, characterized by suboptimal amygdala modulation. These findings provide a potential foundation for future studies investigating how emotion-processing impairments may interact with biological, environmental and genetic risk and contribute to the increased vulnerability to psychiatric disorder in VPT individuals.

\section{Supplementary material}

For supplementary material accompanying this paper visit http://dx.doi.org/10.1017/S0033291716001604.

\section{Acknowledgements}

This study was supported by the Medical Research Council (MRC MR/K004867/1). We would like to thank our participants and the National Institute for Health Research (NIHR) Biomedical Research Centre at South London and Maudsley NHS Foundation Trust and King's College London for their continuous support.

\section{Declaration of Interest}

None.

\section{References}

Aanes S, Bjuland KJ, Skranes J, Løhaugen GCC (2015). Memory function and hippocampal volumes in preterm born very-low-birth-weight (VLBW) young adults. NeuroImage 105, 76-83.

Aarnoudse-Moens CSH, Smidts DP, Oosterlaan J, Duivenvoorden HJ, Weisglas-Kuperus N (2009). Executive function in very preterm children at early school age. Journal of Abnormal Child Psychology 37, 981-993.

Adolphs R (2003). Is the human amygdala specialized for processing social information? Annals of the New York Academy of Sciences 985, 326-340.

Allin M, Rooney M, Cuddy M, Wyatt J, Walshe M, Rifkin L, Murray R (2006). Personality in young adults who are born preterm. Pediatrics 117, 309-316.

Allison T, Puce A, McCarthy G (2000). Social perception from visual cues: role of the STS region. Trends in Cognitive Sciences 4, 267-278.

Amunts K, Kedo O, Kindler M, Pieperhoff P, Mohlberg H, Shah NJ, Habel U, Schneider F, Zilles K (2005). Cytoarchitectonic mapping of the human amygdala, hippocampal region and entorhinal cortex: intersubject variability and probability maps. Anatomy and Embryology 210, 343-352.

Andrews TJ, Ewbank MP (2004). Distinct representations for facial identity and changeable aspects of faces in the human temporal lobe. NeuroImage 23, 905-913.

Ashburner J (2007). A fast diffeomorphic image registration algorithm. Neurolmage 38, 95-113.

Ball G, Boardman JP, Rueckert D, Aljabar P, Arichi T, Merchant N, Gousias IS, Edwards AD, Counsell SJ (2012). The effect of preterm birth on thalamic and cortical development. Cerebral Cortex 22, 1016-1024.

Ball T, Rahm B, Eickhoff SB, Schulze-Bonhage A, Speck O, Mutschler I (2007). Response properties of human amygdala subregions: evidence based on functional MRI combined with probabilistic anatomical maps. PLoS ONE $\mathbf{2}$ e307.

Behzadi Y, Restom K, Liau J, Liu TT (2007). A component based noise correction method (CompCor) for BOLD and perfusion based fMRI. NeuroImage 37, 90-101.

Bickart KC, Dickerson BC, Barrett LF (2014). The amygdala as a hub in brain networks that support social life. Neuropsychologia 63, 235-248. 
Bölte S, Ciaramidaro A, Schlitt S, Hainz D, Kliemann D, Beyer A, Poustka F, Freitag C, Walter H (2015). Training-induced plasticity of the social brain in autism spectrum disorder. The British Journal of Psychiatry 207, 149-157.

Bos AF, Roze E (2011). Neurodevelopmental outcome in preterm infants. Developmental Medicine and Child Neurology 53, 35-39.

Boyd LAC, Msall ME, O'Shea TM, Allred EN, Hounshell G, Leviton A (2013). Social-emotional delays at 2 years in extremely low gestational age survivors: correlates of impaired orientation/engagement and emotional regulation. Early Human Development 89, 925-930.

Brothers L (1990). The social brain: a project for integrating primate behavior and neurophysiology in a new domain. Concepts in Neuroscience 1, 27-51.

Buckner RL, Andrews-Hanna JR, Schacter DL (2008). The brain's default network: anatomy, function, and relevance to disease. Annals of the New York Academy of Sciences 1124, $1-38$.

Burnett AC, Anderson PJ, Cheong J, Doyle LW, Davey CG, Wood SJ (2011). Prevalence of psychiatric diagnoses in preterm and full-term children, adolescents and young adults: a meta-analysis. Psychological Medicine 41, 24632474.

Burnett AC, Scratch SE, Anderson PJ (2013). Executive function outcome in preterm adolescents. Early Human Development 89, 215-220.

Bzdok D, Laird AR, Zilles K, Fox PT, Eickhoff SB (2013). An investigation of the structural, connectional, and functional subspecialization in the human amygdala. Human Brain Mapping 34, 3247-3266.

Collin L, Bindra J, Raju M, Gillberg C, Minnis H (2013). Facial emotion recognition in child psychiatry: a systematic review. Research in Developmental Disabilities 34, 1505-1520.

Conners C (2000). Conners' Continuous Performance Test II Manual. Multi-Health Systems Inc.: Toronto.

Cullen KR, Westlund M, Klimes-Dougan B, Mueller BA, Houri A, Eberly LE, Lim KO (2014). Abnormal amygdala resting-state functional connectivity in adolescent depression. JAMA Psychiatry 71, 1138-1147.

Dahl LB, Kaaresen PI, Tunby J, Handegård BH, Kvernmo S, Rønning JA (2006). Emotional, behavioral, social, and academic outcomes in adolescents born with very low birth weight. Pediatrics 118, e449-e459.

D'Onofrio BM, Class QA, Rickert ME, Larsson $H_{\text {, }}$ Långström N, Lichtenstein P (2013). Preterm birth and mortality and morbidity: a population-based quasi-experimental study. JAMA Psychiatry 70, 1231-1240.

Drevets WC, Raichle ME (1998). Suppression of regional cerebral blood during emotional versus higher cognitive: implications for interactions between emotion and cognition. Cognition and Emotion 12, 353-385.

Eack SM, Wojtalik JA, Barb SM, Newhill CE, Keshavan MS, Phillips ML (2016). Fronto-limbic brain dysfunction during the regulation of emotion in schizophrenia. PLOS ONE 11, e0149297.

Eickhoff SB, Stephan KE, Mohlberg H, Grefkes C, Fink GR, Amunts K, Zilles K (2005). A new SPM toolbox for combining probabilistic cytoarchitectonic maps and functional imaging data. NeuroImage 25, 1325-1335.

Engell AD, Haxby JV (2007). Facial expression and gaze-direction in human superior temporal sulcus. Neuropsychologia 45, 3234-3241.

Eryigit-Madzwamuse S, Strauss V, Baumann N, Bartmann P, Wolke D (2015). Personality of adults who were born very preterm. Archives of Disease in Childhood-Fetal and Neonatal Edition 100, F524-F529.

Fischi-Gómez E, Vasung L, Meskaldji DE, Lazeyras F, Borradori-Tolsa C, Hagmann P, Barisnikov K, Thiran JP, Hüppi PS (2015). Structural brain connectivity in school-age preterm infants provides evidence for impaired networks relevant for higher order cognitive skills and social cognition. Cerebral Cortex 25, 2793-2805.

Gallagher HL, Frith CD (2003). Functional imaging of 'theory of mind'. Trends in Cognitive Sciences 7, 77-83.

Giménez M, Junqué C, Vendrell P, Narberhaus A, Bargalló N, Botet F, Mercader JM (2006). Abnormal orbitofrontal development due to prematurity. Neurology 67, 1818-1822.

Goldberg DP, Williams P (1988). The User's Guide to the General Health Questionnaire. NFER-Nelson: Windsor.

Goossens L, Kukolja J, Onur OA, Fink GR, Maier W, Griez E, Schruers K, Hurlemann R (2009). Selective processing of social stimuli in the superficial amygdala. Human Brain Mapping 30, 3332-3338.

Gousias IS, Edwards AD, Rutherford MA, Counsell SJ, Hajnal JV, Rueckert D, Hammers A (2012). Magnetic resonance imaging of the newborn brain: manual segmentation of labelled atlases in term-born and preterm infants. Neurolmage 62, 1499-1509.

Greicius MD, Krasnow B, Reiss AL, Menon V (2003). Functional connectivity in the resting brain: a network analysis of the default mode hypothesis. Proceedings of the National Academy of Sciences USA 100, 253-258.

Hagmann P, Cammoun L, Gigandet X, Meuli R, Honey CJ, Wedeen VJ, Sporns O (2008). Mapping the structural core of human cerebral cortex. PLoS Biology 6, e159.

Hahn A, Stein P, Windischberger C, Weissenbacher A, Spindelegger C, Moser E, Kasper S, Lanzenberger $R$ (2011). Reduced resting-state functional connectivity between amygdala and orbitofrontal cortex in social anxiety disorder. NeuroImage 56, 881-889.

Harmon HM, Taylor HG, Minich N, Wilson-Costello D, Hack M (2015). Early school outcomes for extremely preterm infants with transient neurological abnormalities. Developmental Medicine and Child Neurology 57, 865-871.

Haxby JV, Hoffman EA, Gobbini MI (2000). The distributed human neural system for face perception. Trends in Cognitive Sciences 4, 223-233.

Healy E, Reichenberg A, Nam KW, Allin MPG, Walshe M, Rifkin L, Murray RM, Nosarti C (2013). Preterm birth and adolescent social functioning - alterations in emotionprocessing brain areas. Journal of Pediatrics 163, 1596-1604.

Hein G, Knight RT (2008). Superior temporal sulcus - it's my area: or is it? Journal of Cognitive Neuroscience 20, 2125-2136.

Hille ETM, den Ouden AL, Saigal S, Wolke D, Lambert M, Whitaker A, Pinto-Martin JA, Hoult L, Meyer R, Feldman 
JF, Verloove-Vanhorick SP, Paneth N (2001). Behavioural problems in children who weigh $1000 \mathrm{~g}$ or less at birth in four countries. Lancet 357, 1641-1643.

Hoffman EA, Haxby JV (2000). Distinct representations of eye gaze and identity in the distributed human neural system for face perception. Nature Neuroscience 3, 80-84.

Hurlemann R, Rehme AK, Diessel M, Kukolja J, Maier W, Walter H, Cohen MX (2008). Segregating intra-amygdalar responses to dynamic facial emotion with cytoarchitectonic maximum probability maps. Journal of Neuroscience Methods $172,13-20$.

Jarros RB, Salum GA, da Silva CTB, Toazza R, de Abreu Costa M, de Salles JF, Manfro GG (2012). Anxiety disorders in adolescence are associated with impaired facial expression recognition to negative valence. Journal of Psychiatric Research 46, 147-151.

Johnson S, Marlow N (2011). Preterm birth and childhood psychiatric disorders. Pediatric Research 69, 11R-18R.

Johnson SC, Baxter LC, Wilder LS, Pipe JG, Heiserman JE, Prigatano GP (2002). Neural correlates of self-reflection. Brain 125, 1808-1814.

Krumhuber EG, Kappas A, Manstead AS (2013). Effects of dynamic aspects of facial expressions: a review. Emotion Review 5, 41-46.

LaBar KS, Crupain MJ, Voyvodic JT, McCarthy G (2003). Dynamic perception of facial affect and identity in the human brain. Cerebral Cortex 13, 1023-1033.

Law Smith MJ, Montagne B, Perrett DI, Gill M, Gallagher L (2010). Detecting subtle facial emotion recognition deficits in high-functioning autism using dynamic stimuli of varying intensities. Neuropsychologia 48, 2777-2781.

Leech R, Braga R, Sharp DJ (2012). Echoes of the brain within the posterior cingulate cortex. Journal of Neuroscience 32, 215-222.

Leech R, Kamourieh S, Beckmann CF, Sharp DJ (2011). Fractionating the default mode network: distinct contributions of the ventral and dorsal posterior cingulate cortex to cognitive control. Journal of Neuroscience 31, 32173224.

Leech R, Sharp DJ (2014). The role of the posterior cingulate cortex in cognition and disease. Brain 137, 12-32.

Leppänen JM, Nelson CA (2009). Tuning the developing brain to social signals of emotions. Nature Reviews Neuroscience 10, 37-47.

Limperopoulos C, Bassan H, Sullivan NR, Soul JS, Robertson RL, Moore M, Ringer SA, Volpe JJ, du Plessis AJ (2008). Positive screening for autism in ex-preterm infants: prevalence and risk factors. Pediatrics 121, 758-765.

Lindström K, Lindblad F, Hjern A (2011). Preterm birth and attention-deficit/hyperactivity disorder in schoolchildren. Pediatrics 127, 858-865.

Mars RB, Neubert FX, Noonan MP, Sallet J, Toni I, Rushworth MFS (2012). On the relationship between the 'default mode network' and the 'social brain'. Frontiers in Human Neuroscience 6, 189.

Mason MF, Norton MI, Van Horn JD, Wegner DM, Grafton ST, Macrae CN (2007). Wandering minds: the default network and stimulus-independent thought. Science 315, 393-395.
Maxim LA, Nowicki SJ (2003). Developmental associations between nonverbal ability and social competence. Facta Universitatis - Series Philosophy, Sociology, Psychology and History 2, 745-758.

Mayer JD, Salovey P, Caruso DR, Sitarenios G (2001). Emotional intelligence as a standard intelligence. Emotions 1, 232-242.

Merboldt KD, Fransson P, Bruhn H, Frahm J (2001). Functional MRI of the human amygdala? NeuroImage 14, 253-257.

Monk CS, Weng SJ, Wiggins JL, Kurapati N, Louro HMC, Carrasco M, Maslowsky J, Risi S, Lord C (2010). Neural circuitry of emotional face processing in autism spectrum disorders. Journal of Psychiatry and Neuroscience 35, 105-114.

Montagne B, de Geus F, Kessels RPC, Denys D, de Haan EHF, Westenberg HGM (2008). Perception of facial expressions in obsessive-compulsive disorder: a dimensional approach. European Psychiatry 23, 26-28.

Montagne B, Kessels RPC, de Haan EHF, Perrett DI (2007). The Emotion Recognition Task: a paradigm to measure the perception of facial emotional expressions at different intensities. Perceptual and Motor Skills 104, 589-598.

Montagne B, Schutters S, Westenberg HGM, van Honk J, Kessels RPC, de Haan EHF (2006). Reduced sensitivity in the recognition of anger and disgust in social anxiety disorder. Cognitive Neuropsychiatry 11, 389-401.

Murphy K, Birn RM, Handwerker DA, Jones TB, Bandettini PA (2009). The impact of global signal regression on resting state correlations: are anti-correlated networks introduced? NeuroImage 44, 893-905.

Nosarti C, Giouroukou E, Healy E, Rifkin L, Walshe M, Reichenberg A, Chitnis X, Williams SCR, Murray RM (2008). Grey and white matter distribution in very preterm adolescents mediates neurodevelopmental outcome. Brain 131, 205-217.

Nosarti C, Nam KW, Walshe M, Murray RM, Cuddy M, Rifkin L, Allin MPG (2014). Preterm birth and structural brain alterations in early adulthood. NeuroImage: Clinical 6, 180-191.

Nosarti C, Reichenberg A, Murray RM, Cnattingius S, Lambe MP, Yin L, MacCabe J, Rifkin L, Hultman CM (2012). Preterm birth and psychiatric disorders in young adult life. Archives of General Psychiatry 69, 610-617.

Ogai M, Matsumoto H, Suzuki K, Ozawa F, Fukuda R, Uchiyama I, Suckling J, Isoda H, Mori N, Takei N (2003). fMRI study of recognition of facial expressions in high-functioning autistic patients. NeuroReport 14, 559-563.

Omizzolo C, Thompson DK, Scratch SE, Stargatt R, Lee KJ, Cheong J, Roberts G, Doyle LW, Anderson PJ (2013). Hippocampal volume and memory and learning outcomes at 7 years in children born very preterm. Journal of the International Neuropsychological Society 19, 1065-1075.

Pearson JM, Heilbronner SR, Barack DL, Hayden BY, Platt ML (2011). Posterior cingulate cortex: adapting behavior to a changing world. Trends in Cognitive Sciences 15, 143-151.

Peng D, Shi F, Shen T, Peng Z, Zhang C, Liu X, Qiu M, Liu J, Jiang K, Fang Y, Shen D (2014). Altered brain network modules induce helplessness in major depressive disorder. Journal of Affective Disorders 168, 21-29. 
Pessoa L, Padmala S, Morland T (2005). Fate of unattended fearful faces in the amygdala is determined by both attentional resources and cognitive modulation. NeuroImage 28, 249-255.

Peters ER, Joseph SA, Garety PA (1999). Measurement of delusional ideation in the normal population: introducing the PDI (Peters et al. Delusions Inventory). Schizophrenia Bulletin 25, 553-576.

Peterson BS, Vohr B, Staib LH, Cannistraci CJ, Dolberg A, Schneider KC, Katz KH, Westerveld M, Sparrow S, Anderson AW, Duncan CC, Makuch RW, Gore JC, Ment LR (2000). Regional brain volume abnormalities and long-term cognitive outcome in preterm infants. Journal of the American Medical Association 284, 1939-1947.

Pinto-Martin JA, Levy SE, Feldman JF, Lorenz JM, Paneth N, Whitaker AH (2011). Prevalence of autism spectrum disorder in adolescents born weighing < 2000 grams. Pediatrics 128, 883-891.

Poljac E, Montagne B, de Haan EHF (2011). Reduced recognition of fear and sadness in post-traumatic stress disorder. Cortex 47, 974-980.

Potharst ES, van Wassenaer-Leemhuis AG, Houtzager BA, Livesey D, Kok JH, Last BF, Oosterlaan J (2013). Perinatal risk factors for neurocognitive impairments in preschool children born very preterm. Developmental Medicine and Child Neurology 55, 178-184.

Power JD, Barnes KA, Snyder AZ, Schlaggar BL, Petersen SE (2012). Spurious but systematic correlations in functional connectivity MRI networks arise from subject motion. NeuroImage 59, 2142-2154.

Puce A, Allison T, Bentin S, Gore JC, McCarthy G (1998). Temporal cortex activation in humans viewing eye and mouth movements. Journal of Neuroscience 18, 2188-2199.

Qin S, Young CB, Duan X, Chen T, Supekar K, Menon V (2014). Amygdala subregional structure and intrinsic functional connectivity predicts individual differences in anxiety during early childhood. Biological Psychiatry 75, 892-900.

Raichle ME, MacLeod AM, Snyder AZ, Powers WJ, Gusnard DA, Shulman GL (2001). A default mode of brain function. Proceedings of the National Academy of Sciences USA 98, 676-682.

Ramasubbu R, Konduru N, Cortese F, Bray S, Gaxiola-Valdez I, Goodyear B (2014). Reduced intrinsic connectivity of amygdala in adults with major depressive disorder. Frontiers in Psychiatry 5, 17.

Rickards AL, Kelly EA, Doyle LW, Callanan C (2001). Cognition, academic progress, behavior and self-concept at 14 years of very low birth weight children. Journal of Developmental and Behavioral Pediatrics 22, 11-18.

Rogers CE, Anderson PJ, Thompson DK, Kidokoro H, Wallendorf M, Treyvaud K, Roberts G, Doyle LW, Neil JJ, Inder TE (2012). Regional cerebral development at term relates to school-age social-emotional development in very preterm children. Journal of the American Academy of Child and Adolescent Psychiatry 51, 181-191.

Rogers CE, Barch DM, Sylvester CM, Pagliaccio D, Harms MP, Botteron KN, Luby JL (2014). Altered gray matter volume and school age anxiety in children born late preterm. Journal of Pediatrics 165, 928-935.

Roy AK, Shehzad Z, Margulies DS, Kelly AMC, Uddin LQ, Gotimer K, Biswal BB, Castellanos FX, Milham MP (2009). Functional connectivity of the human amygdala using resting state fMRI. NeuroImage 45, 614-626.

Saigal S (2014). Functional outcomes of very premature infants into adulthood. Seminars in Fetal and Neonatal Medicine 19, 125-130.

Saxe R, Powell LJ (2006). It's the thought that counts specific brain regions for one component of theory of mind. Psychological Science 17, 692-699.

Schilbach L, Timmermans B, Reddy V, Costall A, Bente G, Schlicht T, \& Vogeley K (2013). Toward a second-person neuroscience. Behavioral and Brain Sciences 36, 393-462.

Schmidt LA, Miskovic V, Boyle MH, Saigal S (2008). Shyness and timidity in young adults who were born at extremely low birth weight. Pediatrics 122, e181-e187.

Scholten MRM, Aleman A, Montagne B, Kahn RS (2005). Schizophrenia and processing of facial emotions: sex matters. Schizophrenia Research 78, 61-67.

Sølsnes AE, Skranes J, Brubakk AM, Løhaugen GCC (2014). Executive functions in very-low-birth-weight young adults: a comparison between self-report and neuropsychological test results. Journal of the International Neuropsychological Society 20, 506-515.

Spittle AJ, Treyvaud K, Doyle LW, Roberts G, Lee KJ, Inder TE, Cheong JLY, Hunt RW, Newnham CA, Anderson PJ (2009). Early emergence of behavior and social-emotional problems in very preterm infants. Journal of the American Academy of Child and Adolescent Psychiatry 48, 909-918.

Sreenivas S, Boehm SG, Linden DEJ (2012). Emotional faces and the default mode network. Neuroscience Letters 506, 229-234.

Stein JL, Wiedholz LM, Bassett DS, Weinberger DR, Zink CF, Mattay VS, Meyer-Lindenberg A (2007). A validated network of effective amygdala connectivity. NeuroImage $\mathbf{3 6}$ 736-745.

Stewart AL, Thorburn RJ, Hope PL, Goldsmith M, Lipscomb AP, Reynolds EOR (1983). Ultrasound appearance of the brain in very preterm infants and neurodevelopmental outcome at 18 months of age. Archives of Disease in Childhood 58, 598-604.

Van Dijk KRA, Sabuncu MR, Buckner RL (2012). The influence of head motion on intrinsic functional connectivity MRI. NeuroImage 59, 431-438.

Vander Wyk BC, Hudac CM, Carter EJ, Sobel DM, Pelphrey KA (2009). Action understanding in the superior temporal sulcus region. Psychological Science 20, 771-777.

Walshe M, Rifkin L, Rooney M, Healy E, Nosarti C, Wyatt J, Stahl D, Murray RM, Allin M (2008). Psychiatric disorder in young adults born very preterm: role of family history. European Psychiatry 23, 527-531.

Wechsler D (1999). Wechsler Abbreviated Scale of Intelligence. The Psychological Corporation: San Antonio, TX.

White TP, Symington I, Castellanos NP, Brittain PJ, Walsh SF, Nam KW, Sato JR, Allin MPG, Shergill SS, Murray RM, Williams SCR, Nosarti C (2014). Dysconnectivity of 
neurocognitive networks at rest in very-preterm born adults. NeuroImage: Clinical 4, 352-365.

Whitfield-Gabrieli S, Moran JM, Nieto-Castañón A, Triantafyllou C, Saxe R, Gabrieli JDE (2011). Associations and dissociations between default and self-reference networks in the human brain. Neurolmage 55, 225-232.

Whitfield-Gabrieli S, Nieto-Castañón A (2012). Conn: a functional connectivity toolbox for correlated and anticorrelated brain networks. Brain Connectivity 2, 125-141.

Williamson KE, Jakobson LS (2014). Social perception in children born at very low birthweight and its relationship with social/behavioral outcomes. Journal of Child Psychology and Psychiatry 55, 990-998.

Witt A, Theurel A, Tolsa CB, Lejeune F, Fernandes L, de Jonge LvH, Monnier M, Graz MB, Barisnikov K, Gentaz E, Hüppi PS (2014). Emotional and effortful control abilities in 42-month-old very preterm and full-term children. Early Human Development 90, 565-569.

Wocadlo C, Rieger I (2006). Social skills and nonverbal decoding of emotions in very preterm children at early school age. European Journal of Developmental Psychology 3, 48-70.

Wolke D, Baumann N, Strauss V, Johnson S, Marlow N (2015). Bullying of preterm children and emotional problems at school age: cross-culturally invariant effects. Journal of Pediatrics 166, 1417-1422.

Woods S, Wolke D, Nowicki S, Hall L (2009). Emotion recognition abilities and empathy of victims of bullying. Child Abuse and Neglect 33, 307-311.

Wright P, Albarracin D, Brown RD, Li H, He G, Liu Y (2008). Dissociated responses in the amygdala and orbitofrontal cortex to bottom-up and top-down components of emotional evaluation. NeuroImage 39, 894-902. 